\title{
DIAGNÓSTICO DA VEGETAÇÃO ARBÓREA E PROPOSTA DE ARBORIZAÇÃO DO RIO CARAHÁ NA CIDADE DE LAGES, SC.
}

\author{
Carlos Augusto Martins dos Reis ${ }^{1}$, Ana Carolina da Silva ${ }^{2}$, Pedro Higuchi ${ }^{2}$, Sheila Trierveiler \\ de Souza ${ }^{1}$, Carla Juliana Silva Madruga Ferreira ${ }^{1}$, Beatriz Michelon ${ }^{1}$, Leticia Moro ${ }^{1}$
}

(recebido em 11.04. 2009 e aceito para publicação em 17.09.2009)

\section{RESUMO}

Este estudo foi realizado no trecho do Rio Carahá que passa na cidade de Lages, SC. Ao longo deste trecho foram estabelecidos sete transectos de $50 \mathrm{~m}$ de comprimento e de largura variável de acordo com a extensão das margens, distribuídas de forma aleatória. Dentro de cada transecto, todas as árvores com CAP (circunferência a altura do peito) $\geq 15$ $\mathrm{cm}$ foram identificadas, medidas e avaliadas quanto às suas características de ocupação espacial, presença de injúrias e de condições fitossanitárias. Com exceção da infestação de alguns indivíduos arbóreos por erva-de-passarinho e fungos, foi verificado que as árvores apresentam boas condições fitossanitárias e nenhum tipo de injúria resultante de vandalismo. A vegetação constitui-se basicamente de espécies exóticas (maior dominância de Populus nigra L.) e bastante espaçadas (baixa densidade de indivíduos). Com a finalidade de aumentar a riqueza de espécies e restabelecer processos ecológicos, sugerese $o$ adensamento e a substituição gradativa por espécies arbóreas nativas que podem oferecer frutos para a fauna aquática e avifauna.

Palavras-chave: arborização urbana, espécies arbóreas nativas, floresta ciliar.

\section{TREE COMPONENT DIAGNOSIS AND URBAN ARBORIZATION PROPOSITION OF RIO CARAHÁ, IN THE CITY OF LAGES, SC}

\begin{abstract}
The present study was realized in a section of Rio Carahá crossing the city of Lages, SC. Seven transects measuring $50 \mathrm{~m}$ long and widths varying according to the margin extension were randomly established along the river margins. Within each transect, every tree with $\mathrm{CBH}$ (circumference at breast height) $\geq 15 \mathrm{~cm}$ were identified, measured and evaluated

\footnotetext{
1. Graduandos do curso de Engenharia Florestal da Universidade do Estado de Santa Catarina. Lages/SC. Rua Vínicius Ricordi Crestani, n. 134, Bairro Petrópolis, Lages - SC. CEP: 88.505-450. E-mail: reis.carlos@ibest.com.br

2. Professores do Departamento de Engenharia Florestal, Universidade do Estado de Santa Catarina, Av. Luiz de Camões, 2090, Bairro Conta Dinheiro, Lages, SC, CEP: 88520-000.
} 
according to spatial occupation traits, injury presence and phytosanitary conditions. Apart from the Mistletoe and fungi infestation of some tree individuals, the observation revealed a good tree phytosanitary condition and no injury presence related to vandalism. The vegetation is sparse (low tree density) and composed mostly by exotic species (high dominance of Populus nigra L.). In order to increase the local tree richness and restore the ecological process, the increment of tree density and the gradual replacement of exotic trees by native ones are suggested. The species to be used in this process are those adapted to flooding prone areas and with fruit production to both avifauna and aquatic fauna.

Key-words: urban arborization, native tree species, riparian forest.

\section{INTRODUÇÃo}

Atualmente, a maior parte da população mundial vive nas cidades, sendo que, no município de Lages isso também ocorre, pois este apresenta uma taxa de urbanização de $98,17 \%$ (IBGE, 2008). Com o aumento das áreas urbanas e o afastamento dos ambientes naturais, houve a necessidade, por parte da população que vive nas cidades, de melhorar a paisagem urbana e a qualidade de vida.

A árvore foi o elemento escolhido para a composição da paisagem urbana por apresentar notável beleza de sua forma e do colorido de suas flores e pela sua importância ecológica (PAIVA E GONÇALVES, 2002). Além disso, há também os serviços ambientais que ela oferece: a amenização climática pelo oferecimento de sombra e redução de temperatura; a proteção dos solos, principalmente os pouco estruturados e com relevo acidentado; a contenção de enchentes pelo aumento da infiltração e redução do escoamento superficial, entre outros (PAIVA E GONÇALVES, 2002).

Toda arborização urbana deve ser bem planejada para que se possa usufruir dos seus benefícios e, para isso, é necessário uma preocupação da administração pública e dos cidadãos.

As margens de rios que passam por áreas urbanas urbanos são áreas estratégicas para o recebimento da arborização urbana, pois, se bem planejada, podem contribuir para a manutenção da qualidade dos cursos da água, e.g. por meio da redução assoreamento, e mitigar eventos de enchentes. Além disso, junto com programas de despoluição, as árvores podem contribuir para a manutenção da vida aquática, melhorando as condições microclimáticas dos cursos da água e fornecendo alimentos, no caso de espécies frutíferas. Em Lages, o principal rio que passa pela cidade é o Carahá, pois cruza uma grande 
extensão da área urbana e é um importante contribuinte do Rio Caveiras, que é a principal fonte de abastecimento de água do município.

Este trabalho teve como objetivos: i) identificar, mensurar e avaliar as árvores plantadas ao longo do Rio Carahá no trecho que passa pela cidade de Lages; ii) verificar problemas da atual arborização neste trecho; iii) propor uma arborização adequada a esse trecho de floresta ciliar.

\section{MATERIAIS E MÉTODOS}

\section{Descrição da área de estudo}

O estudo foi realizado no trecho de floresta ciliar do Rio Carahá que passa por vários bairros da cidade de Lages, SC (Figura 1). Lages está localizada no Planalto Catarinense, região Sul do Brasil, e possui as coordenadas geográficas de latitude $27^{\circ} 48^{\prime} 58^{\prime \prime} S$ e longitude 50¹9'34”W, e a altitude média de 884 m (IBGE, 2008).

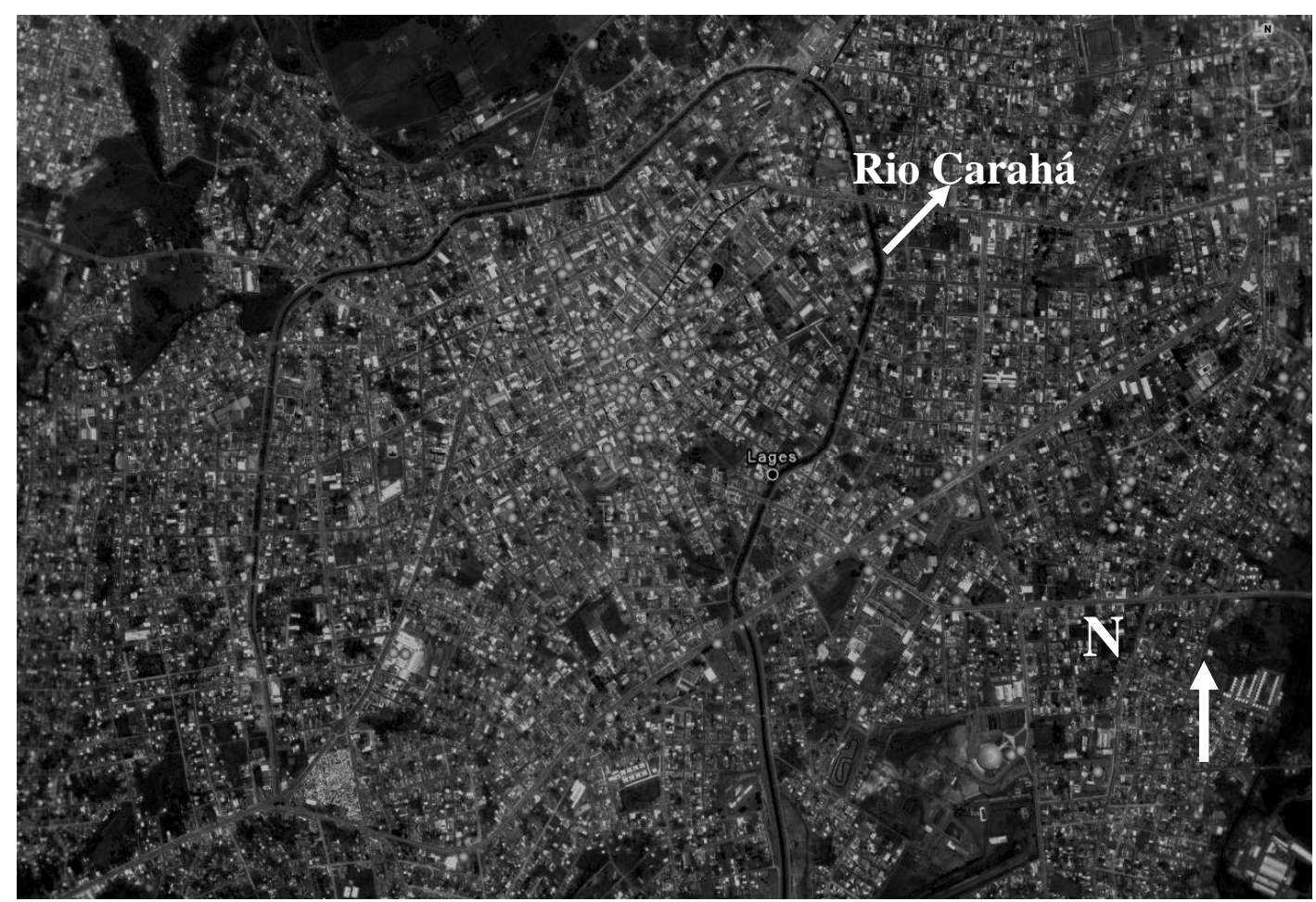

Fonte: Google Earth, 2008.

Figura 1: Imagem aérea do trecho do Rio Carahá que passa pela cidade de Lages, SC, com coordenadas geográficas aproximadas de $27^{\circ} 49^{\prime} 02,35^{\prime \prime} S$ e $50^{\circ} 19^{\prime} 20,72$ ”O.

Lages apresenta temperatura média anual de $15,6^{\circ} \mathrm{C}$ e precipitação pluviométrica média anual de $1.408 \mathrm{~mm}$. A região, em grande parte, é representada pela unidade 
geomorfológica Planalto de Lages, caracterizada por relevo em forma de colina, com altitudes entre 850 e $900 \mathrm{~m}$, chegando até $1.200 \mathrm{~m}$ nos morros mais elevados (SECRETARIA DE ESTADO DE COORDENAÇÃO GERAL E PLANEJAMENTO, 1991). Segundo a classificação do IBGE (1992), a vegetação da região do Planalto Catarinense, pertencente à Mata Atlântica, é classificada como Floresta Ombrófila Mista Montana nas áreas localizadas até $1.000 \mathrm{~m}$ de altitude e Floresta Ombrófila Mista Alto-Montana nas regiões acima de $1.000 \mathrm{~m}$. Nas áreas desmatadas ou de solos mais rasos, ocorre vegetação de campo subtropical caracterizada por agrupamentos herbáceos formados por gramíneas, ciperáceas, compostas, leguminosas e verbenáceas (EMBRAPA, 2004). Os solos predominantes na região são Nitossolos Háplicos e Cambissolos Húmicos, sendo desenvolvido a partir de rochas basálticas (EMBRAPA, 1999).

A população de Lages é de 161.583 habitantes, sendo que a área total do município é de 2.644,31 km² (IBGE, 2008).

\section{Diagnóstico da vegetação arbórea atual}

Foi realizada uma amostragem por meio de sete transectos, distribuídos de forma aleatória, de $50 \mathrm{~m}$ de comprimento e de largura correspondente à largura das margens do rio nos determinados trechos, sendo que a largura média de cada margem é de $8,6 \mathrm{~m}$. Portanto, cada transecto teve, em média, área de $430,4 \mathrm{~m}^{2}$, sendo a área total amostrada aproximada de $3.012,9 \mathrm{~m}^{2}$.

Dentro de cada transecto, todas as árvores com CAP (circunferência a altura do peito) $\geq 15 \mathrm{~cm}$ foram identificadas, medidas e avaliadas quanto às suas características de ocupação espacial, presença de injúrias e condições fitossanitárias. A identificação botânica foi feita por meio de consultas a especialistas e literatura especializada. As espécies de angiospermas foram classificadas em famílias de acordo com o sistema APG II (ANGIOSPERM PHYLOGENY GROUP, 2003) e as grafias dos nomes dos autores foram uniformizadas, seguindo a padronização proposta por Brummitt e Powell (1992). Além das espécies identificadas dentro dos transectos, foi feito um caminhamento em toda a área para complementar a lista florística, onde foram identificados não somente os indivíduos com CAP $\geq 15 \mathrm{~cm}$, mas também indivíduos arbóreos e arbustivos menores. Nos transectos, foram feitas em cada indivíduo arbóreo medidas do CAP (a partir do qual foi calculado o DAP, diâmetro a altura do peito), diâmetro da projeção da copa (DPC), altura total da árvore, altura da primeira ramificação, distância da árvore até o rio, até a rua que margeia o rio e ao indivíduo mais próximo. Além disso, foi analisado o estado geral das árvores, as injúrias, a fitossanidade, a intensidade do ataque de pragas, assim como o local do ataque 
(flor, frutos, folhas ou caule), as condições de poda, se foi o caso, a inclinação do fuste, a interferência do sistema radicular na pavimentação da rua, a interferência da copa em elementos urbanos e no trânsito de pedestres e de veículos.

A estrutura do componente arbóreo foi descrita a partir do cálculo, para cada espécie, dos parâmetros quantitativos clássicos propostos por Mueller-Dombois e Ellemberg (1974): densidade absoluta, freqüência absoluta, dominância absoluta expressa pela área basal, densidade relativa, freqüência relativa, dominância relativa e valor de importância (VI). Também foram feitos gráficos da distribuição diamétrica e de altura de toda a comunidade. As amplitudes de classe e as classes de distribuição de diâmetro e de altura foram definidas pelo método estatístico, sendo que as classes diamétricas foram: Classe 1, de 4,7 a 15,3 cm; Classe 2, de 15,3 a 25,9 cm; Classe 3, de 25,9 a $36,5 \mathrm{~cm}$; Classe 4, de 36,5 a 47,1 cm; Classe 5, de 47,1 a 57,8 cm; Classe 6, de 57,8 a 68,4 cm; Classe 7 , de 68,4 a $79,0 \mathrm{~cm}$. As classes de altura foram: Classe 1, de 3,0 a 5,5 cm; Classe 2, de 5,5 a 8,0 cm; Classe 3, de 8,0 a 10,5 cm; Classe 4, de 10,5 a 13,0 cm; Classe 5, de 13,0 a $15,5 \mathrm{~cm}$; Classe 6 , de 15,5 a $18,0 \mathrm{~cm}$; Classe 7 , de 18,0 a 20,5 cm.

\section{Proposta de arborização}

A proposta de arborização foi feita com base no diagnóstico realizado com a localização das deficiências da atual arborização e com base na composição florística e estrutural de florestas ciliares nativas de fitofisionomias semelhantes (estudos de Barddal et al., 2004; Marcelino, 2001; e observações pessoais).

\section{RESULTADOS E DISCUSSÃO}

\section{Diagnóstico da vegetação arbórea atual}

Dentro dos sete transectos foram encontrados 46 indivíduos pertencentes a três espécies arbóreas exóticas: Populus nigra L. (31 indivíduos), Salix babylonica L. (11 indivíduos) (ambas da família Salicaceae) e Ligustrum japonicum Thunb. (4 indivíduos) (família Oleaceae) (Tabela 1). A área foi caracterizada pela baixa riqueza de espécies, pela baixa densidade de indivíduos (152,68 ind./ha) e pela elevada dominância de $P$. nigra (70,65\%), que também obteve a maior densidade de indivíduos (102,89 ind./ha) e a maior freqüência, ocorrendo em todas as unidades amostrais (Tabela 2). Também foi observado, na região sul da cidade, um trecho com aproximadamente $2 \mathrm{~km}$ de área ciliar sem vegetação arbórea. 
TABELA 1: Resultado das variáveis medidas nos sete transectos alocados nas margens do Rio Carahá na cidade de Lages, SC.

\begin{tabular}{|c|c|c|c|c|c|c|c|c|}
\hline Espécie & $\begin{array}{l}\text { Número de } \\
\text { indivíduos }\end{array}$ & $\begin{array}{l}\text { DAP } \\
\text { médio } \\
(\mathrm{cm})\end{array}$ & $\begin{array}{c}\text { DPC } \\
\text { médio } \\
(\mathrm{m})\end{array}$ & $\begin{array}{c}\text { Altura } \\
\text { média } \\
(\mathrm{m})\end{array}$ & $\begin{array}{l}\text { Altura média } \\
\text { da primeira } \\
\text { ramificação } \\
\text { (m) }\end{array}$ & $\begin{array}{c}\text { Distância } \\
\text { média das } \\
\text { árvores ao } \\
\text { rio }(\mathrm{m})\end{array}$ & $\begin{array}{c}\text { Distância } \\
\text { média das } \\
\text { árvores à } \\
\text { rua }(\mathrm{m})\end{array}$ & $\begin{array}{c}\text { Distância } \\
\text { média ao } \\
\text { indivíduo } \\
\text { mais } \\
\text { próximo (m) }\end{array}$ \\
\hline Populus nigra L. & 31 & 44,9 & 6,7 & 10,4 & 1,7 & 2,8 & 4,3 & 9,5 \\
\hline Médias & & 37,1 & 6,1 & 8,3 & 1,2 & 2,5 & 3,2 & 9,6 \\
\hline
\end{tabular}

TABELA 2: Parâmetros fitossociológicos das espécies encontradas nos transectos alocados nas margens do Rio Carahá na cidade de Lages, SC. $\mathrm{H}$ = altura máxima de cada espécie, em m; DA = densidade absoluta, em ind./ha; $\mathrm{DR}=$ densidade relativa, em \%; DoA = dominância absoluta, em $\mathrm{m}^{2} / \mathrm{ha} ; \mathrm{DoR}=$ dominância relativa, em \%; $\mathrm{FA}=$ freqüência absoluta, em \%; $\mathrm{FR}=$ freqüência relativa, em \%; $\mathrm{VI}=$ valor de importância, em \%.

\begin{tabular}{lcccccccc}
\hline \multicolumn{1}{c}{ Espécie } & H & DA & DR & DoA & DoR & FA & FR & VI \\
\hline Populus nigra L. & 18 & 102,89 & 67,39 & 17,89 & 70,65 & 100,00 & 53,85 & 63,96 \\
Salix babylonica L. & 15 & 36,51 & 23,91 & 6,85 & 27,04 & 42,86 & 23,08 & 24,68 \\
Ligustrum japonicum Thunb. & 8 & 13,28 & 8,70 & 0,58 & 2,30 & 42,86 & 23,08 & 11,36 \\
\hline Total & & 152,68 & 100,00 & 25,32 & 100,00 & 185,71 & 100,00 \\
\hline
\end{tabular}


Dos 46 indivíduos amostrados, apenas oito apresentaram inclinação do fuste. As copas dos indivíduos não ocasionam interferência em elementos urbanos, sendo que as únicas construções presentes entre as árvores são as pontes. Em poucos locais, também há a presença de fiação elétrica e postes, sem que estes prejudiquem o desenvolvimento das árvores.

Apesar do tráfego intenso de veículos nas avenidas adjacente à floresta ciliar e das primeiras ramificações das árvores serem baixas, em média 1,2 m (Tabela 1) com 27 indivíduos apresentando a primeira ramificação abaixo de 1,8 m, a interferência das árvores no trânsito dos veículos é baixa. Isso ocorre porque existe um bom distanciamento dos indivíduos da avenida, com uma média de 3,2 m e pelas podas periódicas realizadas pela prefeitura nos indivíduos mais próximos da rua. Apenas quatro indivíduos mal localizados nas unidades amostrais, situados a uma distância menor do que $2 \mathrm{~m}$ da avenida, interferiam no trânsito dos ônibus com suas copas no momento das avaliações. Esta situação contribuiu para a ocorrência de podas mal conduzidas em um indivíduo de Salix babylonica. Também não havia interferência do sistema radicular das árvores amostradas na pavimentação das avenidas. Devido à ausência de pavimentação para trânsito de pedestres, as ramificações baixas não são um problema e não foram observadas injúrias nas árvores resultantes de vandalismo.

Foram observados fungos em indivíduos de Populus nigra, de Ligustrum japonicum e de Salix babylonica, cochonilha em um indivíduo de Ligustrum japonicum e erva-de-passarinho em 10 indivíduos de Populus nigra. Apesar disso, o estado fitossanitário geral das árvores foi bom, pois a intensidade do ataque de pragas foi baixa, ocorrendo predominantemente no caule e, em poucos casos, nas folhas.

Além das espécies arbóreas encontradas nos transectos, foram localizadas, por meio do caminhamento na área, as espécies exóticas Cupressus sempervirens L. (Cupressaceae), Thuja orientalis L. (Cupressaceae), Lagerstroemia indica L. (Lythraceae), Eriobotrya japonica (Thunb.) Lindl. (Maloideae), Melia azedarach L. (Meliaceae), Musa paradisiaca L. (Musaceae), Eucalyptus sp. (Myrtaceae), Ligustrum sinense Lour. (Oleaceae), Chusquea sp. (Poaceae), Hovenia dulcis Thumb. (Rhamnaceae) e Citrus sp. (Rutaceae), e as espécies nativas Schinus terebinthifolius Raddi (Anarcadiaceae), Araucaria angustifolia (Bert.) Kuntze (Araucariaceae), Syagrus rommanzoffiana (Cham.) Glassman (Arecaceae), Handroanthus albus (Cham.) Mattos (Bignoniaceae), Sapium glandulosum (L.) Morong (Euphorbiaceae), Bauhinia forficata Link (Fabaceae), Senna pendula (Willd.) H.S.Irwin \& Barneby (Fabaceae), Campomanesia xanthocarpa O.Berg (Myrtaceae), Eugenia involucrata DC. (Myrtaceae), Eugenia uniflora L. (Myrtaceae), Plinia sp. (Myrtaceae), Psidium cattleianum Sabine (Myrtaceae) e Solanum mauritianum Scop. (Solanaceae). A maior 
riqueza de espécies encontrada na florística do que nos transectos ocorreu, principalmente, porque na florística não foi determinado um CAP mínimo para a amostragem, como nos transectos (CAP $\geq 15 \mathrm{~cm}$ ). A maior parte dos indivíduos identificados na florística possuía menor porte e, mesmo quando estavam dentro dos transectos, não atingiam o CAP mínimo, estando na fase inicial de crescimento. Alguns dos exemplares encontrados de espécies nativas, provavelmente, não foram plantados, e provém de regeneração natural.

Todas as árvores amostradas nos transectos foram plantadas, provavelmente, na mesma época, sugerindo uma floresta composta, predominantemente, de indivíduos equiâneos, que hoje, associado à baixa riqueza de espécies, ocasiona uma estrutura vertical pouco diferenciada, com a maioria dos indivíduos ocorrendo em estratos verticais próximos (Figura 2A). Esse padrão estrutural comporta pouca diversidade de nichos, o que, por sua vez, permite menor biodiversidade de outros vegetais (plantas epífitas, por exemplo) e animais (HUNTER JR., 1990). Uma estrutura vertical mais estratificada é desejável, pois irá influenciar positivamente na riqueza, na diversidade, no crescimento e na produção de biomassa, sendo um importante indicador de sustentabilidade ambiental (SOUZA et al., 2003).

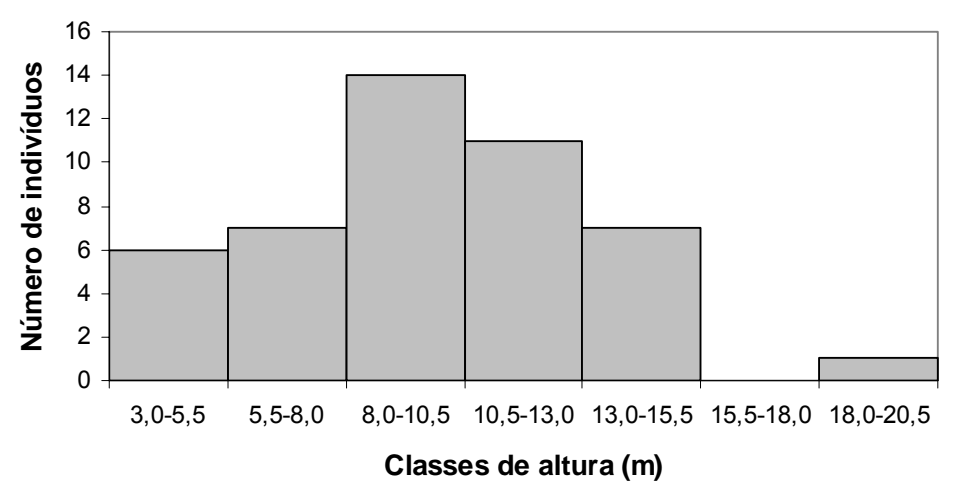

A

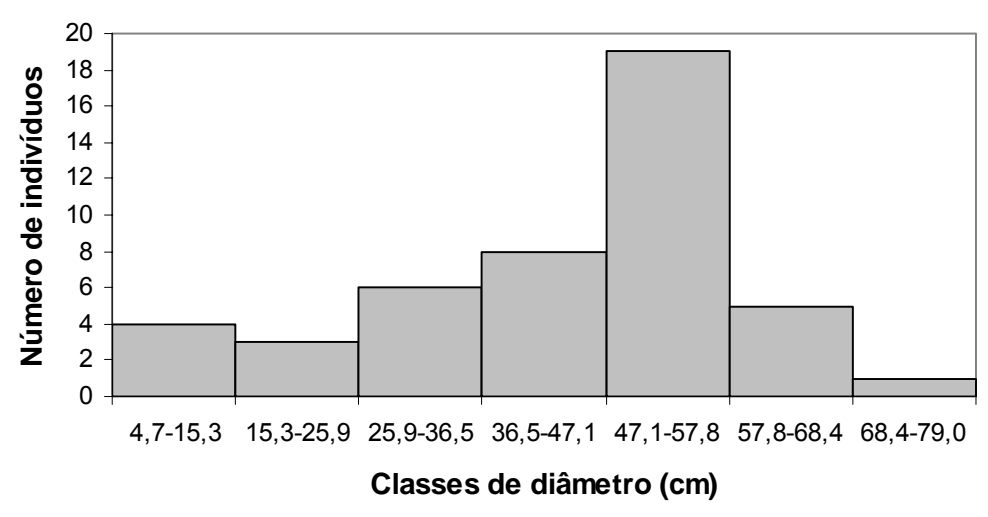

B

Figura 2. Estrutura da altura $(A)$ e diamétrica $(B)$ da comunidade arbórea nas margens do Rio Carahá em Lages, SC. 
Além disso, conforme demonstrado na Figura 2B, a floresta apresenta estrutura horizontal com muitos indivíduos nas maiores classes de diâmetro e poucos indivíduos nas menores classes. Porém, o desejável é que a comunidade florestal apresente uma estrutura diamétrica próxima ao "J invertido", ou exponencial negativa, com muitos indivíduos de menores diâmetros e poucos indivíduos de grande porte, pois esta característica pode ser um indicativo de equilíbrio da floresta e de possuir um bom "estoque" regenerativo (MEYER, 1943, 1952, 1953; LEAK, 1964).

Uma floresta somente com indivíduos de grande porte plantados em baixa densidade pode comprometer também suas funções ambientais, tais como proteção e contenção dos solos. Na região de Lages, isso pode ser observado nas enchentes frequentes que ocorrem na cidade. A não contenção eficiente de sedimentos carreados por escoamento superficial aumenta o risco de assoreamento do curso d'água e, conseqüentemente, de enchentes em épocas de chuvas mais intensas.

As enchentes em Lages pelo extravasamento do Rio Carahá foram observadas no ano de 2008, quando houve grande intensidade de chuvas que causou o transbordamento do rio, invadindo as ruas e residências mais próximas ao rio. Os dois motivos principais para esse evento foram: i) pequena largura da faixa ciliar do rio; ii) arborização inadequada no trecho de floresta ciliar, com pouca densidade de indivíduos chegando, em alguns trechos, a ocorrência de nenhuma arborização.

Populus nigra, apesar de ser uma espécie indicada para ser plantada em florestas ciliares, por ser tolerante a solos saturados (LORENZI et al., 2003), possui baixa densidade de indivíduos na área ciliar estudada, não sendo possível exercer sua função de agregação dos solos pelas raízes com total eficácia. Aumentar a densidade desta espécie não seria a melhor estratégia, pois é uma espécie pioneira, com baixa capacidade competitiva, que necessita de crescimento à plena luz, e não é tolerante ao maior adensamento. Neste caso, a solução seria uma arborização com maior riqueza, utilizando espécies adaptadas a plena luz, intercalada com espécies de sub-bosque, de forma que os diferentes estratos no perfil vertical da floresta e no perfil do solo sejam ocupados pela parte aérea e sistema radicular das árvores.

\section{Proposta de arborização}

Devido às deficiências discutidas acima, é sugerido que se faça a substituição gradativa das espécies exóticas por nativas, sendo que estas deverão ser plantadas com maior adensamento que o atual, obedecendo ao adensamento natural de espécies nativas de florestas ciliares (por exemplo, densidade da floresta ciliar estudada por Barddal et al., 2004: 1630 ind./ha). Esta substituição deverá ser feita, inicialmente, com 
o plantio de espécies nativas tolerantes ao sombreamento na fase inicial de crescimento, e, posteriormente, quando essas já estiverem estabelecidas, deverá ser feita a abertura gradativa do dossel, por meio da remoção das espécies exóticas adultas. Dessa forma, evita-se o revolvimento e a exposição do solo, reduzindo a ocorrência de erosão. Esta substituição visará o aumento da riqueza de espécies e o restabelecimento dos processos ecológicos da floresta ciliar.

Baseado em alguns estudos de florística em florestas ombrófilas mistas aluviais (estudos de Barddal et al., 2004; Marcelino, 2001; e observações pessoais), pode-se indicar as seguintes espécies nativas para o plantio ao longo da floresta ciliar do Rio Carahá: Schinus lentiscifolius Marchand (aroeira, família Anacardiaceae), Ilex theezans Mart. ex Reissek (caúna, família Aquifoliaceae), Oreopanax fulvus Marchal (figueira-domato, família Araliaceae), Weinmannia humilis Engl. (gramimunha, família Cunoniaceae), Sebastiania brasiliensis Spreng. (leiteiro, família Euphorbiaceae), Sebastiania commersoniana (Baill.) L.B.Sm. \& Downs (branquilho, família Euphorbiaceae), Nectandra megapotamica (Spreng.) Mez (canela-preta, família Lauraceae), Acca sellowiana (O.Berg) Burret (goiabeira serrana, família Myrtaceae), Campomanesia xanthocarpa O.Berg (guaviroba, família Myrtaceae), Eugenia pyriformis Cambess. (uvaia, família Myrtaceae), Myrcia splendens (Sw.) DC. (guamirim-da-folhafina, família Myrtaceae), Myrsine umbellata Mart. (capororocão, família Myrsinaceae), Podocarpus lambertii Klotzsch (pinheiro-bravo, família Podocarpaceae), Zanthoxylum kleinii (R.S.Cowan) P.G.Waterman (mamica-de-cadela, família Rutaceae), Casearia decandra Jacq. (guaçatunga, família Salicaceae), Xylosma ciliatifolia (Clos) Eichler (sucará, família Salicaceae), Allophylus guaraniticus (A.St.-Hil.) Radlk. (chal-chal, família Sapindaceae), Matayba elaeagnoides Radlk. (camboatá-branco, família Sapindaceae) e Drimys brasiliensis Miers (casca-d'anta, família Winteraceae). Grande parte destas espécies possui os frutos apreciados pela ictiofauna e avifauna, que disseminam as suas sementes, com destaque para as espécies das famílias Anacardiaceae, Lauraceae, Myrtaceae, Myrsinaceae, Salicaceae e Sapindaceae.

$\mathrm{Na}$ região sul da cidade, onde foi observado o trecho de aproximadamente $2 \mathrm{~km}$ sem a ocorrência de espécies arbóreas, é recomendado que se faça o plantio das mesmas espécies nativas sugeridas acima. Porém, como esse trecho está totalmente destituído de vegetação arbórea, deve ser realizado o plantio respeitando o processo de sucessão ecológica, plantando-se, inicialmente, as espécies pioneiras, como Schinus lentiscifolius, Sebastiania commersoniana, Acca sellowiana, Myrsine umbellata e Drimys brasiliensis Miers, e espécies secundárias iniciais, como Casearia decandra, Allophylus guaraniticus e Matayba elaeagnoides, seguidas das espécies secundárias 
tardias, como Nectandra megapotamica e Campomanesia xanthocarpa, e das espécies clímax, como Zanthoxylum kleinii.

\section{CONCLUSÕES}

A densidade e a riqueza das espécies arbóreas nas margens do trecho do Rio Carahá que corta a cidade de Lages são baixas. O predomínio é de espécies arbóreas exóticas que apresentam boas condições fitossanitárias e sem injúrias causadas por vandalismo.

Como a vegetação hoje existente constitui-se, basicamente, de espécies exóticas plantadas em baixa densidade, sugere-se, com a finalidade de aumentar a riqueza de espécies e restabelecer processos ecológicos, o adensamento e a substituição gradativa por espécies de árvores nativas.

\section{REFERÊNCIAS BIBLIOGRÁFICAS}

ANGIOSPERM PHYLOGENY GROUP. An update of the angiosperm phylogeny group classification for the orders and families of flowering plants: APG II. Botanical Journal of the Linnean Society, v.143, p. 399-436, 2003.

BARDDAL, M. L.; RODERJAN, C. V.; GALVÃO, F.; CURCIO, G. R. Caracterização florística e fitossociológica de um trecho sazonalmente inundável de floresta aluvial, em Araucária, PR. Ciência Florestal, v.14, n.2, p. 37-50, 2004.

BRUMMITT, R. K.; POWELL, C. E. Authors of plant names. Kew: Royal Botanic Gardens; 1992.

EMBRAPA. Sistema brasileiro de classificação de solos. Rio de Janeiro: Embrapa Solos, 1999. 412p.

EMBRAPA. Solos do Estado de Santa Catarina. Rio de Janeiro: Embrapa Solos, 2004. 726p. (Boletim de Pesquisa e Desenvolvimento, 46).

GOOGLE EARTH, Imagem do satélite obtida pelo google earth versão 4.3, http://earth.google.com.br/ Acesso em: 06 jun 2008.

HUNTER Jr, M. L. Wildlife forests and forestry: principles of managing forests for biological diversity. New Jersey: Prentice-Hall, 1990. 370p.

IBGE. Manual técnico da vegetação brasileira. Rio de Janeiro: Fundação Instituto Brasileiro de Geografia e Estatística, 1992. 123p. (Série: Manuais técnicos em geociências n. 1).

IBGE. Censo demográfico 2007. Rio de Janeiro: IBGE. http://www.ibge.gov.br/ Acesso em 10 out 2008. 
LEAK, W. B. An expression of diameter distribution for unbalanced, uneven-aged stands and forests. Forest Science, v.10, n.1, p. 39-50, 1964.

LORENZI, H.; SOUZA, H. M.; TORRES, M. A. V.; BACHER, L. B. Árvores exóticas no Brasil: madeireiras, ornamentais e aromáticas. Nova Odessa: Instituto Plantarum, 2003. 368p.

MARCELINO, D. W. B. (coordenador) Árvores do reservatório da UHE Machadinho. Piratuba: Machadinho Energética S. A. (MAESA), 2001. 101p.

MEYER, H. A. Management without rotation. Journal of Forestry, v.41, p. 126-132, 1943.

MEYER, H. A. Structure, growth, and drain in balanced uneven-aged forests. Journal of Forestry, v.50, n.2, p. 85-92, 1952.

MEYER, H. A. Forest mensuration. State College, Pa.: Renns Valley Publishers, 1953. $357 p$.

MUELLER-DOMBOIS, D.; ELLENBERG, H. Aims and methods of vegetation ecology. New York: Wiley, 1974.

PAIVA, H. N.; GONÇALVES, W. Florestas urbanas: planejamento para melhoria da qualidade de vida v.2. Viçosa: Editora Aprenda Fácil, 2002. 180p.

SECRETARIA DE ESTADO DE COORDENAÇÃO GERAL E PLANEJAMENTO - Santa Catarina. Atlas escolar de Santa Catarina. Rio de Janeiro: Aerofoto Cruzeiro, 1991. $96 \mathrm{p}$.

SOUZA, D. R.; SOUZA, A. L.; GAMA, J. R. V.; LEITE, H. G. Emprego de análise multivariada para estratificação vertical de florestas ineqüiâneas. Revista Árvore, v.27, n.1, p. 59-63, 2003. 